\title{
Invisibilidade humana
}

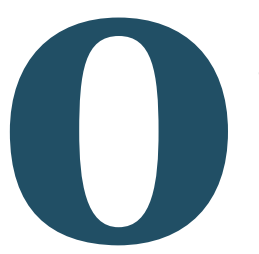

fator humano no setor de serviços, no varejo de massas em particular, sofreu mutações ao longo da história. Num primeiro momento, quando seenfatizava a necessidadedeum atendimento amigável com o cliente, ele era considerado recurso tangível importante no desfecho da venda. Hoje, quando o setor altera suas premissas a favor do mercado de experiências, ele deve tornar-se invisível para que o acesso à experiência com o produto apareça em primeiro plano para o cliente.

por IsleideA. Fontenelle FGKEAESP

Hoje em dia, o ponto de encontro entre varejo e fator humano é a idéia de "varejo-experiência". Tal idéia baseia-se na importância de vender uma "experiência" ao cliente, e não apenas uma mercadoria. Isso exige, em contraparti$\mathrm{da}$, um novo tipo de relacionamento com o cliente, o que, por sua vez, traz novos desafios à gestão das pessoas envolvidas nessa relação.

Mutações no varejo. Do ponto de vista da história do varejo, à primeira vista, esse desafio não parece tão 
novo assim. Em seu livro, 0 Declínio do Homem Público, Richard Sennett nos mostra como, desde o surgimento das lojas de departamentos nas principais capitais européias e norte-americanas em meados do século XIX, os comerciantes varejistas já trabal havam com o "caráter de espetáculo" de suas lojas. Investiram em decorações de vitrines - uma novidade absoluta na época - e revestiram suas mercadorias, produzidas em massa, de significações pessoais que iam além de seus valores utilitários, em busca de evocar lembranças e provocar emoções.

sa, os empregados "vendem, antes de tudo, seus serviços". Diante disso, diz o autor, tornou-se necessário desenvolver, nesse novo tipo de empregado, a habilidade de "lidar com pessoas", não mais clientes usuais, conhecidos até mesmo pelo nome, mas uma grande massa de estranhos urbanos, e em nome de um negócio do qual não era o proprietário.

Mills apresenta em seu livro quais as necessidades de treinamento desse novo tipo de empregado para que ele pudesse atender ao desafio do novo comércio, estabelecendo o vínculo entre produção em massa, distribuição em massa e consumo individual. No rol dessas necessidades, muitas repetidas ainda hoje à exaustão, temos, por exemplo, como definir bem o perfil de um bom vendedor, considerando características essenciais como "capacidade para dar-se bem com as pessoas e cooperar com

O utra grande novidade nessa nova forma de comércio foi a implantação do preço fixo: as mercadorias passaram a ter seus preços claramente definidos e os compradores podiam circular livremente, apenas olhando, sem a obrigação de ter que comprar - isso porque a figura do vendedor mudou drasticamente na passagem do antigo mercado central da cidade para essa nova forma de comércio varejista.

É que no antigo mercado os preços do varejo flutuavam e o vendedor era uma espécie de ator, fazendo todo tipo de encenação possível para fazer valer o seu preço. 0 comprador, por sua vez, também o acompanhava nessa encenação teatral, nesse jogo em que estavam incluídos a pechincha e os rituais de compra e venda que esse tipo de mercado envolvia. Já nas lojas de departamentos, quando o volume de vendas retirou do proprietário a relação direta com o comprador e passou a requerer um número maior de empregados, o preço fixo resolveu o problema, evitando que o funcionário tivesse esse poder de barganha.

Mercado de personalidade. Em meados do século $X X$, o sociólogo norte-americano $C$. Wright Mills nos forneceu o quadro desse novo tipo de negócios e de funcionários: se no mundo do pequeno empresário os homens vendiam mercadorias, no comércio varejista da grande empre- os outros, facilidade para abordar pessoas e conversar com elas, e uma aparência agradável".

N esse sentido, não é de hoje que se descobriu a importância do fator humano no campo do varejo. Há que se considerar, entretanto, porque esse discurso ressurge agora como al go novo e quais as relações de continuidade e de ruptura do "comércio da experiência", do qual se fala hoje, com esse tempo histórico de longa duração.

A era do acesso. Quando caminhamos para uma economia virtual, em uma sociedade marcada pela falta de tempo em que as coisas podem ser compradas com o clique de um mouse, até que ponto a "velha loja", de tijolo e cimento, que vende mercadorias concretas, será necessária? Como afirma o antropólogo norte-americano Paco Underhill - apontado pela mídia de negócios como um dos maiores especialistas em varejo do mundo - , o lojista contemporâneo não disputa mais o cliente com a loja vizinha, mas com o trio "tecnologia, lazer e bem-estar". Trata-se de uma briga pela atenção do consumidor em tempos de TV a cabo, Internet e celular, de um Iado, e de saturação das compras de outro.

É nesse contexto que cresce, cada vez mais, o discurso de que uma ida às compras é uma busca pela "experiência em si", mais do que pelo prazer da aquisição. Logo, o dis- 
curso correnteé de que o varejo do futuro precisaria investir nesta que parece ser sua última fronteira: 0 acesso à experiência. De acordo com o sociólogo italiano Francesco Morace- realizador de uma pesquisa, em vários países europeus, na qual buscou encontrar as relações entre consumo e felicidade - , agora é "a nossa experiência sensorial que define o que é válido. Os produtos e os serviços devem emocionar, não é mais suficiente a imagem ou o entretenimento. É necessária a experiência profunda e autêntica".

E Morace não está sozinho nessa constatação. Os novos mercadores da experiência informam que o varejo moderno está recorren do a uma ressensibilização do corpo, a um novo treino dos sentidos, buscando resgatar cheiros, cores, sabores e a experiência do grande mercado de outrora, que teria se perdido com a padronização e pasteurização dos produtos e serviços. É isso quetambém defende 0 arquiteto Eric Kutne, ao afirmar que o varejo precisa retomar a experiência do grande mercado livre: aguçar os sentidos, levar à experimentação, promover uma grande performance teatral.

Por isso mesmo, esse arquiteto vai até os mercados orientais (Istambul, na Turquia, por exemplo) a fim de se inspirar e fornecer consultorias ao varejo ocidental. A experiência parece ter se tornado, portanto, a grande moeda de troca dessa nova etapa da economia. Mas de qual noção de experiência estamos falando?

A invisi bi li dade como val or. Q uando tratam de responder essa questão, os especial istas em varejo não titubeiam em afirmar que tal experiência se consegue com um mix de arquitetura, design e produtos adequados ao tipo de consumidor que se quer atingir, além de um ambiente agradável que atenda as necessidades do consumidor usual. Um exemplo seria um espaço que receba bem as crianças, que são cada vez mais determinantes para a decisão de compra.

$\mathrm{N}$ ada que grandes marcas globais como

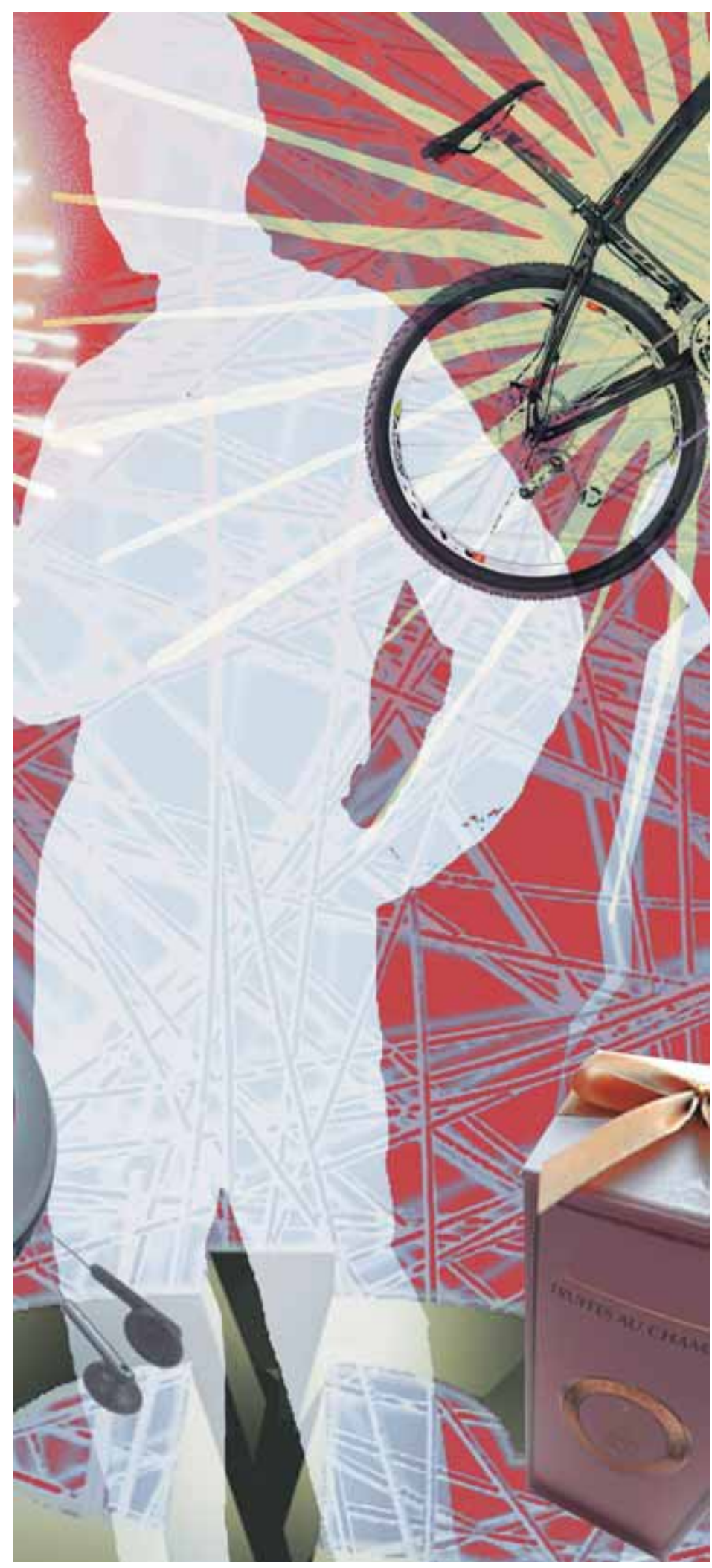


Disney e McDonald's, por exemplo, já não venham nos ensinando há, pelo menos, meio século. Fazem isso com suas arquiteturas de reasseguramento e gestões de pessoas baseadas em forte formação para um tipo de relação com o cliente fundada em um serviço a partir do qual se realce a "experiência total" fornecida por essas marcas.

Segundo o McDonald's isso se deveu sempre a dois fatores: um atendimento amigável, até mesmo "amoroso" com o cliente, e um serviço conveniente em termos de velocidade e qualidade. Segundo dados da Corporação, em 2005 o M cDonald's investiu R\$ 22 milhões em formação, treinamento e motivação de seus funcionários brasileiros e alocou parte desse investimento em uma gincana que

vídeos até jogos de realidade virtual", prometem, tão somente, o direito de o consumidor "experimentar": tocar, provar, sentir o gosto, o cheiro, enfim, experienciar. Segundo o gerente de relações de mídia da M etreon, Charles Earnest, "esse é um jeito diferente de ver a tecnologia. A tecnologia que apresentamos é de ponta... Você pode ver como isso se encaixa no seu dia-a-dia".

Se, de um lado, esse tipo de loja é uma forma de "treinar para o acesso" por meio das novas tecnologias, por outro é uma maneira de fazer frente à própria concorrência que 0 acesso à nova tecnologia está provocando no varejo tradicional, através da compra on-line. Daí porque, nas palavras de Karl Novatney, ex-gerente geral da loja Metreon, "criar uma boa experiência éa única maneira de trazer as pessoas até as lojas".

Para exemplificar melhor 0 relação ao fator humano é que ele conti nuará sendo fundamental mente necessário, desde que se torne invisível : ele deverá se confundir a tal ponto com a experiência a ser oferecida ao cliente que terá de se di luir nela.

levará 31 funcionários à Copa do Mundo de Futebol, a se realizar este ano, na Alemanha. 0 propósito da competição, segundo press release da companhia, foi "reunir elementos de qualificação de mão-de-obra com o de motivação dos funcionários", baseado na idéia de que "o funcionário mais satisfeito atende melhor o cliente".

Em que pese a importância desse tipo de serviço para o varejo de massas, ainda em expansão no caso do Brasil, a tendência mundial não parece mais indicar que a figura do "vendedor amoroso" interesse a novos formatos de experiência que o varejo do futuro nos promete.

Novos formatos de lojas, desde aquelas que vendem produtos tradicionais, tais como cosméticos, bolsas e tênis, a produtos de alta tecnologia, como a Metreon, localizada em San Francisco (EUA), fundada pela Sony e projetada como "um lugar urbano moderno... onde as pessoas podem passar o dia experimentando, desde câmeras de interaction of technology, culture and marketing, publicado em 2005, "é necessária uma imersão completa na experiência para que o jogador não pense que está interagindo com um computador. Deve-se convencê-lo de estar imerso numa experiência e que controla suas fantasias. É isso que define a mágica do jogo e, nesse caso, a tecnologia tem que ser tão boa que se faça invisível!".

O funcionário invisível. Quando a experiência se tornar a mercadoria em si, a única pela qual se paga, um dos aspectos absolutamente novos com relação ao "fator humano" é que ele continuará sendo fundamentalmente necessário, desde que, também, se torne invisível. Ele de verá se confundir a tal ponto com a experiência a ser oferecida que terá de se diluir nela. A "necessidade de ser impecável", sob o risco de aparecer negativamente, já éo discurso que ronda esse novo tipo de consumo da experiência. 


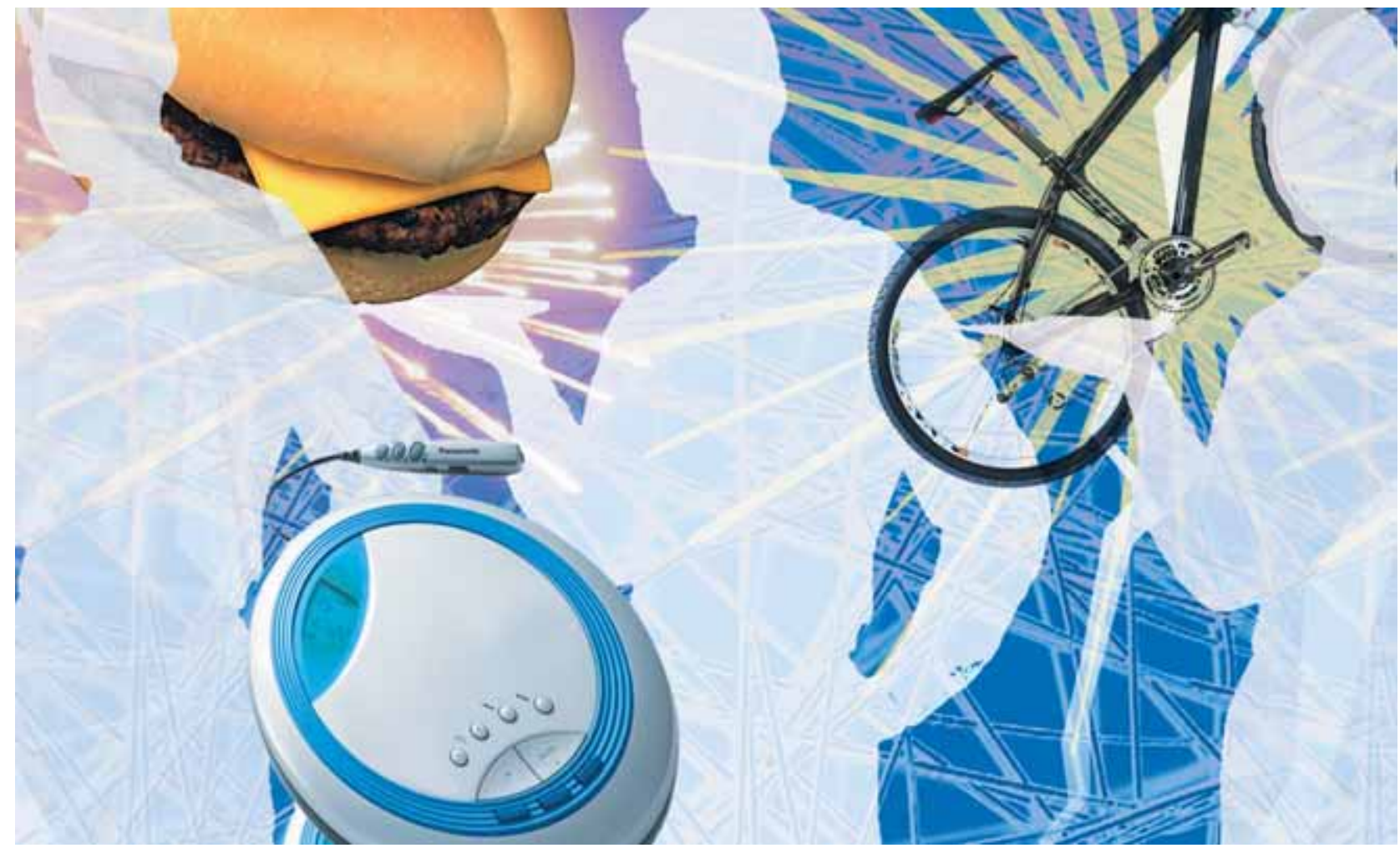

De fato, se o que está em jogo na "era do acesso" não é mais a aquisição do produto, mas o vivenciar uma "experiência", esta passa a ser apontada como um valor que precisa ser pesquisado e medido. Trata-se da idéia, presente no livro 0 Imaterial, de André Gorz, de que "o vaIor intrínseco do que se faz (...) se torna tão importante quanto o valor-dinheiro obtido no mercado". Em outras palavras, o que conta, cada vez mais, é a qualidade da coordenação dos aspectos sistêmicos e das relações entre os empregados.

Que tipo de profissional deve estar preparado para isso? Como o fator humano deverá ser enfocado, desenvolvido, para dar conta de tal desafio? Penso que enfrentar essa questão, mesmo que não se tenha, ainda, uma resposta pronta, é mais produtivo do que apelar para categorias gastas como motivação, envolvimento com cliente etc. M ais do que pensar em treinar e recompensar funcionários individualmente - à maneira do velho modelo do vendedor "personalista" da época de Wright Mills - , 0 desafio é desenvolver um coletivo que vende para um comprador que se torna, cada vez mais, individualizado.
Essa idéia do coletivo tem o propósito de remeter, de um lado, para o trabal ho em equipe como um somatório de habilidades e competências que deve resultar na "experiência final" a ser vivenciada pelo consumidor, portanto, de um trabalho produzido coletivamente. De outro, permite se pensar na possibilidade da experiência desse coletivo de trabalho, ou seja, na atribuição de significado, de sentido para o que se faz. Vender experiência também requer um mergulho na "experiência coletiva", a fim de que ela possa ser veiculada como tal. A recompensa de existir um significado coletivo do trabalho - pertencimento - carrega um sentido utópico e se apresenta como o desafio maior a ser alcançado nesse empreendimento de vender experiência.

\section{IsleideA. Fontenelle}

Profa. do Departamento de Fundamentos Sociais e Jurídicos da Administração da FGV-EAESP

Pós-doutora em psicologia social pela PUC-SP

E-mail: isleide@fgvsp.br 